Actas del Seminario Internacional Destinos Turísticos Inteligentes:

nuevos horizontes en la investigación y gestión del turismo

Universidad de Alicante, 26 y 27 de octubre de 2017

\title{
Análise das contribuições participativas ao Paraná turístico 2026: pacto para um destino inteligente
}

\author{
Marcelle Miskalo-Cruz \\ Universidade Federal do Paraná - UFPR, Brasil, Mestrado em Turismo \\ miskalo@gmail.com
}

Renata C. Klos Universidade Federal do Paraná - UFPR, Brasil, Doutorado em Geografia renatacklos@gmail.com

Yure S. Lobo

Universidade Federal do Paraná - UFPR, Brasil, Mestrado em Turismo yureslobo@gmail.com

José Manoel Gândara

Universidade Federal do Paraná - UFPR, Brasil, Professor e Pesquisador no Mestrado em Turismo e Mestrado e Doutorado em Geografia jmggandara@yahoo.com.br

\section{Resumo}

Considerando que Destino Turístico Inteligente pode ser definido como esforços integrados de um destino a fim de obter e agregar informações relevantes provenientes de infraestruturas físicas e dados de órgãos públicos e privados, aliado ao uso de tecnologias para transformar essas informações em experiências de qualidade e valor agregado aos turistas, o Estado do Paraná, sul do Brasil, desenvolveu em 2016 o plano estratégico «Paraná Turístico 2026: Pacto para um Destino Turístico Inteligente». O plano é resultado de processo de construção conjunta e pactuada entre o poder público, iniciativa privada e sociedade civil, envolvendo atores de todo o Estado e de suas 14 Regiões Turísticas. Este trabalho busca perceber a situação atual, segundo os gestores públicos e privados dos municípios turísticos, lideranças e agentes de mercado do setor turístico, bem como analisar as contribuições participativas colhidas durante o processo de elaboração do plano, perceber qual a visão de futuro destes e suas convergências para o conceito de Destinos Turísticos Inteligentes. 
Actas del Seminario Internacional Destinos Turísticos Inteligentes:

nuevos horizontes en la investigación y gestión del turismo

Universidad de Alicante, 26 y 27 de octubre de 2017

Palavras-chave: Destino Turístico Inteligente; Paraná Turístico 2026; Governança; Competitividade; Inovação.

\section{Abstract}

Whereas that Smart Tourist Destination can be defined as integrated efforts of a destination in order to obtain and add relevant information from physical infrastructures and data from public and private agencies, through technologies to transform the information into quality experiences and added value for tourists, the State of Paraná, southern Brazil, developed in 2016 the strategic plan «Paraná Turístico 2026: Pact for a Smart Tourist Destination». The plan is result of a process of joint construction between public agency, private initiative and civil society, involving actors from all over the State and its 14 Tourist Regions. This article seeks to understand the current situation according to the public and private managers of the tourist municipalities, leaderships and market agents of touristic sector, and also to analyze the participatory contributions that were collected during the process of drawing up the plan, to understand the vision of the future of them and their convergence to the concept of Smart Tourist Destinations.

Keywords: Smart Tourist Destination; Paraná Turístico 2026; Governance; Competitiveness; Innovation.

\section{Introdução}

O Paraná ocupa o posto de terceiro destino nacional em número de turistas, totalizando 15.9 milhões e o quarto destino brasileiro no ranking de chegada de turistas internacionais, com 837 mil, obtendo receita de cerca de $R \$ 5,7$ bilhões de reais no ano de 2015 (MTur, 2016). Foz do Iguaçu se configura como a terceira cidade mais visitada por turistas estrangeiros a lazer com $13.5 \%$ e Curitiba, também em terceiro lugar, contudo no segmento de Negócios, Eventos e Convenções com 4.2\% da preferência de turistas estrangeiros (MTur, 2016). Quanto ao número de seus visitantes, em 2012, estes foram de 2.574.200 e 3.653.300, respectivamente (Paraná Turismo, 2014, p. 46 e 42). Soma-se a este quadro a existência de uma boa infraestrutura de estradas, aeroportos, ferrovias, portos, usinas geradoras de energia elétrica, unidades de conservação, patrimônio cultural e a abertura do Porto de Paranaguá para os navios de cruzeiros, configurando o Paraná como destino que vem se consolidando de forma crescente. 
Actas del Seminario Internacional Destinos Turísticos Inteligentes:

nuevos horizontes en la investigación y gestión del turismo

Universidad de Alicante, 26 y 27 de octubre de 2017

O Estado, no que tange as suas políticas públicas de turismo, mantém desde 2003 um enfoque de planejamento turístico regional alinhado à Política Nacional de Turismo no sentido de planejar coerentemente a atividade turística em seu território, a partir de alianças estratégicas expressas em um Conselho Estadual de Turismo que busca estabelecer esforços conjuntos para consecução de objetivos comuns a partir das sinergias oferecidas pelos principais atores do território e, deste modo, acaba por se destacar como modelo de atuação na condução de seu planejamento turístico-territorial. Em 2016 foi realizado o lançamento do direcionamento estratégico de longo prazo denominado de plano «Paraná Turístico 2026: Pacto para um Destino Inteligente», resultado de um processo de construção conjunta e pactuada entre o poder público, iniciativa privada e sociedade civil, envolvendo atores de todo o Estado e das suas 14 Regiões Turísticas. Esse documento alinha-se à Política de Turismo do Paraná (Lei n.o 15.973/2008) ${ }^{1}$ e apresenta uma visão de futuro desafiadora, objetivos, estratégias, metas e macroprogramas a serem atingidos no horizonte temporal de 2016 a 2026, que tem como base os princípios da sustentabilidade, o alinhamento institucional, a adequação de orçamentos, a melhoria da comunicação interna e externa e, também, o uso racional do patrimônio natural e cultural, apontando para o desafio de construir um Destino Turístico Inteligente -DTI.

É neste contexto que se estabelece o objetivo deste trabalho, que é de analisar as contribuições participativas que foram levantadas durante o processo de elaboração do plano, perceber qual a visão de futuro dos atores sociais participantes do processo e a convergência dos mesmos para o conceito de DTI.

Ademais, o presente trabalho integra a proposta «Nuevos enfoques para la planificación y gestión del território turístico: conceptualización, análisis de experiências y problemas. Definición de modelos operativos para destinos turísticos inteligentes» (projeto CSO2014-59193-R) do Programa Estatal Espanhol de I+D+I (Investigación, Desarollo y Innovación) do Ministério da Economia e Competitividade, coordenado pela Universidade de Alicante, com a participação das Universidades de Málaga, Oviedo, Múrcia, Politécnica de Madri, bem como a Universidade Federal do Paraná.

1. PARANÁ. Lei Estadual 15.973/2008. Dispõe sobre a Política de Turismo do Paraná, conforme especifica e adota outras providências. Disponível em: <legislacao.pr.gov.br/legislacao/>. 
Actas del Seminario Internacional Destinos Turísticos Inteligentes:

nuevos horizontes en la investigación y gestión del turismo

Universidad de Alicante, 26 y 27 de octubre de 2017

\section{Metodologia}

A metodologia empregada para a elaboração deste trabalho foi a pesquisa bibliográfica e documental que Dencker (2007) define como sendo a síntese do tema, a qual segue sequência lógica e que se apresentam conceitos e referenciais. A pesquisa bibliográfica que subsidiou a revisão da literatura e o embasamento teórico foi realizada por meio de periódicos e artigos científicos relacionados aos temas: governança, sustentabilidade, qualidade, competitividade, marketing, inovação, gestão de destinos turísticos e DTI. Também foi realizada abordagem qualitativa a partir da análise de conteúdo que Bardin (1994, p. 18) resume como «técnica de investigação que tem por finalidade a descrição objetiva, sistemática e quantitativa do conteúdo manifesto da comunicação». Creswell (2010, p. 26) ainda dita que a pesquisa qualitativa é usada para estudar problemas sociais ou humanos de forma a explorar e entender o significado que os indivíduos/grupos atribuem a estes problemas; porquanto a quantitativa é um meio para testar teorias objetivas, examinando a relação entre as variáveis para que possam ser medidas para que os dados numéricos possam ser analisados por procedimentos estatísticos.

A metodologia para a elaboração do plano teve por base um processo estratégico-participativo, no qual foram realizadas consultas através oficinas em cada uma das 14 regiões turísticas do Paraná, em 11 grupos focais compostos por representantes do negócio turístico estadual (especialistas em Turismo; órgãos públicos afins ao Turismo; federações do setor e Sistema $S^{2}$; operadores da Associação Brasileira das Operadoras de Turismo -BRAZTOA; instituições representativas das atividades turísticas do setor, a saber: agenciamento, hospedagem, eventos, transporte, alimentação, guias de turismo e jornalistas de turismo), bem como através de consulta pública, resultando no envolvimento direto de 655 participantes, sendo que destes, 439 participaram das oficinas e grupos focais. $\mathrm{O}$ objetivo foi o de elevar o envolvimento e comprometimento do setor com o planejamento turístico em curso,

2. Sistema S é o termo do conjunto de organizações de entidades corporativas para o treinamento profissional, assistência social, consultoria, pesquisa e assistência técnica. É composto por: Serviço Nacional de Aprendizagem Industrial (SENAI); Serviço Social do Comércio (SESC); Serviço Social da Indústria (SESI); e Serviço Nacional de Aprendizagem do Comércio (SENAC). Existem ainda os seguintes: Serviço Nacional de Aprendizagem Rural (SENAR); Serviço Nacional de Aprendizagem do Cooperativismo (SESCOOP); e Serviço Social de Transporte (SEST). 
Actas del Seminario Internacional Destinos Turísticos Inteligentes:

nuevos horizontes en la investigación y gestión del turismo

Universidad de Alicante, 26 y 27 de octubre de 2017

gerando conteúdo e subsídios para sua elaboração (CEPATUR, 2016). Assim, a partir de uma mesma pergunta orientadora de futuro sobre o "Paraná Turístico 2026» empregada para cada eixo estratégico (a saber: governança e sustentabilidade; qualidade e competitividade; marketing e inovação) foram consolidados gráficos com categorias analíticas e número de citações referentes a cada uma dessas categorias. Além dos eixos, os gráficos foram organizados e apresentados por tipo de atividade de planejamento participativo realizada (oficinas regionais e grupos focais) permitindo, desta forma, inferir as principais contribuições que serviram de subsídios para o processo de planejamento estratégico do referido Plano (CEPATUR, 2016).

\section{Destinos turísticos inteligentes}

Destinos turísticos possuem diferentes significados, podendo ser abordado de diversas formas, tais como: unidades em vários níveis geográficos, mas sem fronteiras geográficas distintas e imagens resultantes da prática social (Framke, 2002); conjunto de instituições e atores localizados em um espaço físico ou virtual onde transações relacionadas a marketing e atividades ocorrem, desafiando a tradicional dicotomia de produção-consumo (Saraniemi \& Kylänen, 2010); subsistema no espaço comum entre dois sistemas mais amplos: o do turista e o do geográfico, que beneficiam ambos e que devem ser interpretados, planejados e geridos de acordo com os elementos individuais (Barrado Timón, 2004); e, para Jovicic (2016), os atributos geográficos são o núcleo da base do destino turístico, entre outros.

Nam \& Pardo (2011) afirmam que as cidades têm crescido rapidamente e que o crescimento populacional urbano tem gerado sérias ameaças, tais como deterioração das condições de transporte, riscos físicos, entre outros. Uma maneira utilizada por órgãos públicos para contornar tal fato é aderir a noção de inteligência ${ }^{3}$ associada diretamente à obtenção de sucesso às suas políticas, estratégias e programas para alcançar o desenvolvimento sustentável, o crescimento econômico sólido e a melhoria da qualidade de vida dos seus cidadãos ${ }^{4}$. Por sua vez, os destinos adaptam-se a essas mudanças e usufruem das oportunidades que são criadas (Ivars Baidal, Solsona Monzonís \& Gíner Sánchez, 2016) e surgem então os Destinos Turísticos

3. Tradução livre do inglês: «smart».

4. Center on Governance. (2003). SmartCapital Evaluation Guidelines Report: Performance Measurement and Assessment of Smart Capital. Ottawa, Canada: University of Ottawa. 
Actas del Seminario Internacional Destinos Turísticos Inteligentes: nuevos horizontes en la investigación y gestión del turismo

Universidad de Alicante, 26 y 27 de octubre de 2017

Inteligentes, que têm por objetivo melhorar as experiências dos turistas através de tecnologias de informação e comunicação - TIC, de acordo com Ávila Muñoz \& García Sánchez (2013) e Boes, Buhalis \& Inversini (2015). Um destino inteligente evidencia o uso de tecnologias aplicadas ao turismo ao integrar atividades e recursos físicos e informativos para melhorar o serviço e a experiência do turista, bem como inovar a gestão e aumentar a competividade (Gretzel, Sigala, Xiang et al., 2015; Jiang, 2013); impõe aos sistemas a vinculação do termo às TIC, o desenvolvimento sustentável e a gestão eficiente dos recursos (Luque Gil, Zayas Fernández \& Caro Herrero, 2015). Para Blanco (2015), é um território turístico que possui projeto e objetivo definido de criar desenvolvimento sustentável baseado nas limitações e capacidades locais, potencializando a integração da tecnologia em toda a relação criadora de valor do destino, bem como reforçar e incorporar ações entre gestores públicos e privados a fim de promover maior competitividade do destino. Completando, a Sociedad Estatal para la Gestión de la Innovación y las Tecnologías Turísticas - SEGITTUR (2015, p. 100) define Destino Turístico Inteligente como:

Destinos inovadores, consolidados sobre uma infraestrutura tecnológica de vanguarda que garante o desenvolvimento sustentável do território, acessível a todos, que facilita a interação e integração do visitante ao entorno e que melhora sua experiência no destino e a qualidade de vida dos residentes daquele local.

\section{Gestão de destinos turísticos}

Pode-se perceber que o poder político-administrativo detém uma grande responsabilidade: a de gerir este processo. É razoável conceituar gestão como ato de gerir, gerenciar, administrar uma unidade e todos os seus respectivos recursos, inclusive os humanos (Rezende \& Castor 2005). Faz parte do processo a preocupação com o incremento estrutural que facilite $o$ desenvolvimento econômico, objetivando a melhoria da qualidade de vida da população, que desperte o interesse das grandes empresas em instalar-se em seu entorno e que ainda atraia novos visitantes e turistas, gerando mais empregos e renda através da execução de políticas (Bac Lija, 2013). Políticas públicas, de acordo com Teixeira $(2002$, p. 2) «são diretrizes, princípios norteadores de ação do poder público; regras e procedimentos para as relações entre o poder público e a sociedade; mediações entre atores da sociedade e Estado». Atualmente, a governança se situa no debate da 
Actas del Seminario Internacional Destinos Turísticos Inteligentes: nuevos horizontes en la investigación y gestión del turismo

Universidad de Alicante, 26 y 27 de octubre de 2017

política e da investigação turística como um novo enfoque de governo capaz de dar resposta à crescente complexidade de gestão de destinos turísticos em um contexto de permanente preocupação com a sustentabilidade destes. Desta forma, chama à atenção refletir como geri-los de forma a satisfazer as necessidades de seus integrantes, fazendo o uso racional dos recursos disponíveis e buscando a mais ampla participação social no momento de se desenhar, executar e avaliar a política de desenvolvimento turístico. Assim, a governança se configura como um modelo útil para colocar em prática, ou seja, operacionalizar o exercício efetivo da sustentabilidade nos destinos turísticos (Butler, 1999; Getz \& Jamal, 1994; Hall, 2011; Irving, 2005; Pulido \& Pulido, 2013; Pulido Fernández \& Pulido Fernández, 2014; Velasco González, 2013, 2014).

A literatura aponta para o fato de que para se alcançar maior sucesso na operacionalização da sustentabilidade no turismo, torna-se fundamental incorporar o conceito de governança, pois o mesmo envolve um amplo e complexo conjunto de atores públicos e privados, baseando-se na flexibilidade, na parceria e participação voluntária dos vários representantes dos interesses sociais existentes, potencializando o alcance dos princípios da sustentabilidade (Farinós, 2008; Pulido Fernández \& Pulido Fernández, 2014; Velasco González, 2013, 2014). Conforme relatório do PNUD (1996), governança pode ser entendida como um conjunto de processos, instituições e práticas, através das quais os cidadãos e os diferentes grupos articulam seus interesses e posições, formando um complexo sistema de elaboração de políticas e de tomada de decisões mais vasto que a arena estatal. Desta forma, a governança é um conceito amplo, pois abrange desde a relação entre governo e empresas privadas, como também organizações do terceiro setor, entidades de classe, além de outros mecanismos informais que, segundo Rosenau (2000, p. 16) «fazem com que as pessoas e as organizações dentro de sua área de atuação tenham uma conduta determinada, satisfaçam suas necessidades e respondam às suas demandas».

O uso cada vez mais frequente do termo no âmbito turístico fez avançar seu conceito, que pode ser definido como:

Uma prática de governo que pode ser medida, que visa gerir o turismo em diferentes níveis de governo através de formas de coordenação, colaboração e/ou de cooperação eficazes, transparentes e sujeitas à prestação de contas o que ajudará a alcançar os objetivos de interesse coletivo compartilhado por redes de atores envolvidos no setor com o objetivo de 
Actas del Seminario Internacional Destinos Turísticos Inteligentes: nuevos horizontes en la investigación y gestión del turismo

Universidad de Alicante, 26 y 27 de octubre de 2017

desenvolver soluções e oportunidades através de acordos baseados no reconhecimento das interdependências e responsabilidades compartilhadas (Pulido Fernandez \& Pulido Fernandez, 2014, p. 687).

De encontro a este conceito, Velasco González (2014, p. 19) reforça que a governança do turismo ou a governança turística é:

A busca de novas formas de tomada de decisões coletivas sobre assuntos que implicam a gestão de conflitos de interesses e que tratam de impulsionar processos de inovação social, o fortalecimento dos atores mais fracos do sistema e a mudança das dinâmicas turísticas que geram impactos negativos.

Considerando que entre os destinos turísticos coexistem uma multiplicidade de atores, cujas percepções e interesses em relação à atividade turística são diversos e, portanto, nem sempre coincidem, o conceito de governança turística toma ainda mais força como mecanismo capaz de reconhecer a complexidade da construção da coesão social (material, simbólica e temporal) do território, associada às relações de poder. Neste sentido, também se faz necessário introduzir o conceito de governança em rede como um modo mais plural e democrático de fazer gestão, com base na confiança, reciprocidade e lealdade (Barrado Timón, 2004; Blanco \& Gomá, 2003; Ejarque, 2005; Framke, 2002; Ivars Baidal, Rodríguez Sánchez, Vera Rebollo \& Acebal, 2014; Pearce, 2014, 2016). Nesta perspectiva, fica evidente que tanto o planejamento quanto a melhoria da competitividade e da sustentabilidade de um destino turístico passa, necessariamente, pela compreensão de que a operacionalização destes conceitos e incorre no constante e consciente esforço do exercício da responsabilidade compartilhada e da cooperação de todos os atores envolvidos como pilares de sustentação de todo o processo, aspectos estes presentes no conceito de governança; o que facilita, também, o consenso e a aprendizagem durante o planejamento e a gestão do destino turístico (Flores \& Mendes, 2014; Velasco González, 2010).

\section{Contextualização do Paraná turístico 2026}

Para o desenvolvimento do processo, destaca-se a importância do ambiente político-institucional e das políticas públicas como processos interdependentes que subsidiam a elaboração de planos de desenvolvimento mais efetivos, uma vez que quão melhor for o ambiente político-institucional, maiores serão as oportunidades de estabelecer formas de decisões coletivas que 
Actas del Seminario Internacional Destinos Turísticos Inteligentes:

nuevos horizontes en la investigación y gestión del turismo

Universidad de Alicante, 26 y 27 de octubre de 2017

sustentem os processos de tomada de decisões, assim como proporcionem um papel mais ativo dos diferentes atores sociais no processo (Hall, 2001; Pearce, 2015; Velasco González, 2014).

A organização planejada para o desenvolvimento da atividade turística no Paraná com enfoque regional se iniciou pela Política Estadual de Turismo 2003-2007, documento composto por um conjunto de estratégias, objetivos, metas e ações com finalidade de promover o desenvolvimento socioeconômico da atividade no Estado e que serviu de base para a Lei Estadual de Turismo n. $15.973 / 2008$. Todo o processo foi articulado por meio do Conselho Paranaense de Turismo - CEPATUR, tendo como objetivo estabelecer o Paraná como destino turístico desenvolvido de forma eficaz, dentro dos padrões de sustentabilidade, qualidade e competitividade (CEPATUR, 2016). É importante ressaltar que, em dezembro de 2002, foi criada a Secretaria de Estado do Turismo do Paraná -SETU, efetivamente instalada em 2003, mesmo ano que, em nível federal, foi instituído o Ministério do Turismo -MTur, ambos se constituindo como órgãos exclusivos de planejamento e gestão do setor, cada um em sua escala de atuação, mas cujas competências galgam a combinação máxima dos instrumentos defendidos por Velasco González (2011, 2013, 2014) como fundamentais para a conformação de uma política de turismo. Desta forma, pode-se afirmar que, ao longo de 13 anos (período de 2003 a 2015) a atividade foi desenvolvida com base no órgão estadual de turismo, conselho estadual de turismo e três planos de desenvolvimento (Política Estadual de Turismo 2003-2007, Plano de Desenvolvimento do Turismo do Paraná 2008-2011 e o Plano de Desenvolvimento do Turismo do Paraná 2012-2015), todos desenvolvidos de forma participativa e alinhados às prerrogativas do Plano Nacional de Turismo, do Programa de Regionalização do Turismo, bem como da Lei Estadual de Turismo do Paraná, com ações, indicadores e metas a atingir (CEPATUR, 2016). Nesta perspectiva não se descarta os diversos processos que o antecederam, uma vez que as políticas públicas são resultado do acúmulo de ações no tempo e do trabalho organizado de diversos atores públicos e privados; o que se pretende é explicitar o crescente processo de elaboração e execução de políticas e planejamento turístico postos em marcha no Paraná nos últimos anos, assim como o reconhecimento da sua institucionalidade.

Em 2013, a área de Turismo passou a ser incorporada, no âmbito estadual, à Secretaria de Esportes, passando a ter como braço executor a autarquia Paraná Turismo, a articulação institucional se manteve por meio do 
Actas del Seminario Internacional Destinos Turísticos Inteligentes: nuevos horizontes en la investigación y gestión del turismo

Universidad de Alicante, 26 y 27 de octubre de 2017

CEPATUR, que, a partir de um amplo processo de construção conjunta e pactuada entre o poder público, iniciativa privada e a sociedade civil, com objetivo de apontar os caminhos futuros, propôs o desenvolvimento do «Paraná Turístico 2026: Pacto para um Destino Inteligente». De partida, surge com um planejamento indicativo, multi-institucional, descentralizado e de longo prazo. $O$ documento define visão, objetivos, estratégias, metas e macroprogramas como forma de promover a transformação que se almeja para o turismo paranaense, no horizonte temporal de dez anos e configura-se também como instrumento de comunicação com a opinião pública, com as populações envolvidas e as instituições, bem como com potenciais investidores e, de um modo geral, com os agentes da transformação (CEPATUR, 2016). A proposta não é ser um instrumento rígido de planejamento, mas sim, orientador de ações que se destinam a transformar a realidade atual e o alcance de objetivos comuns em favor do destino turístico, por meio de um processo contínuo que gere compromissos dos diversos atores do território em favor do desenvolvimento do turismo. Para tanto apresenta três eixos estratégicos de ação, que são: 1) Governança e Sustentabilidade: onde pretende desenvolver o turismo por meio de planejamento estratégico, articulado e incorporado às políticas de vários setores independentes, compatibilizando questões federais, macrorregionais, estaduais, municipais e difundir-se como uma atividade que contribui para o desenvolvimento socioeconômico, conservação ambiental, valorização cultural, qualidade de vida e o uso racional dos recursos existentes, incentivando investimentos baseados em estudos e pesquisas quantitativas e qualitativas; 2) Qualidade e Competitividade: onde o objetivo é desenvolver, ampliar, qualificar e dinamizar a oferta turística (atrativos, equipamentos, serviços e infraestrutura) disponibilizada pelo poder público e pela iniciativa privada, qualificando-a dentro de padrões de excelência que possibilitem maior competitividade nos diferentes mercados, e; 3) Marketing e Inovação: onde o objetivo é fomentar e promover o destino Paraná e seus produtos turísticos nos mercados nacionais e internacionais, através de ações de divulgação e comercialização inovadoras que propiciem uma maior acessibilidade do Estado aos consumidores efetivos e potenciais (CEPATUR, 2016, p. 8).

Acredita-se que a vinculação do planejamento estratégico ao participativo utilizado na metodologia da elaboração do plano seja um caminho mais viável para subsidiar o que Manente (2008) indica como sendo uma gestão bem sucedida, ou seja, aquela que é capaz de levar os destinos turísticos 
Actas del Seminario Internacional Destinos Turísticos Inteligentes: nuevos horizontes en la investigación y gestión del turismo

Universidad de Alicante, 26 y 27 de octubre de 2017

rumo ao novo milênio e que deve ser baseada na organização dos recursos locais, na coordenação e gestão da produção do turismo, na gestão e controle das relações entre as partes interessadas, na segmentação de mercado e linhas de produtos, e, finalmente, a na criação e gestão do valor produzido pelo sistema de turismo para todos os atores envolvidos: público e do setor privado, os turistas e a comunidade local, integralmente baseados no conhecimento e na informação. Isso corrobora com a visão de futuro buscada pelo plano:

Em 2026 o Destino Turístico Paraná será reconhecido, no mercado nacional e internacional, como um destino turístico de qualidade, inteligente e inovador, com base na melhoria contínua da competitividade da sua oferta, valorizando e respeitando suas características e diferenciais para gerar valor e experiências positivas. Estará alicerçado no capital humano qualificado, na modernização pública e privada, no uso adequado das TIC, na excelência ambiental e cultural e na governança colaborativa e pactuada pelos atores locais; com o turismo posicionado como atividade econômica estratégica e sustentável, promotora da qualidade de vida de seus habitantes (CEPATUR, 2016, p. 97).

\section{Resultados e discussão}

O conjunto das mudanças estruturais no setor turístico traz a necessidade de novos enfoques, fazendo emergir o modelo DTI como referência para gestão dos destinos (Ivars Baildal, Solsona Monzonís \& Giner Sánchez, 2016). Apesar de ainda pouco explorado pelo turismo, já se observa um movimento de localidades promovendo iniciativas com o objetivo de tornarem-se atrativas como DTI (Blanco, 2015; Graziano, 2014; Nam \& Pardo, 2011). As revoluções tecnológicas continuam alterando o relacionamento entre pessoas e organizações, ampliando as possibilidades de interação e conexão entre os indivíduos e o acesso à informação, reforçando que o uso da tecnologia é menos determinado pelo instrumento, em si, que pelas possibilidades que a mesma apresenta, tal como o estabelecimento de redes, conexões e a oferta de recursos que abrem espaços para a inovação, sistemas de inteligência e conhecimento, cujo impacto transcende todos os setores da atividade econômica, incluindo o turismo. Este novo paradigma constitui um importante fator de modificação de comportamento social, exigindo das empresas e dos destinos turísticos mudanças no sentido de acompanhar o ritmo e tirar maior proveito da tecnologia (Buhalis \& Amaranggana, 2014; Castells, 1999; 
Actas del Seminario Internacional Destinos Turísticos Inteligentes:

nuevos horizontes en la investigación y gestión del turismo

Universidad de Alicante, 26 y 27 de octubre de 2017

Gretzel, Sigala, Xiang, et al., 2015; Ivars Baidal, Solsona Monzonís \& Gíner Sánchez, 2016; Pérez, 2010). As análises a seguir consideram este contexto e, sobretudo, o fato de que a governança, a sustentabilidade, a qualidade, a competitividade, o marketing, a inovação e o modelo DTI se reforçam mutuamente, vez que as TIC passam a ser um meio poderoso para a promoção e operacionalização destes elementos, que devem ser vistos como transversais e complementares.

\subsection{Governança e Sustentabilidade}

O modelo DTI estabelece a governança do destino como conceito chave que inter-relaciona outros cinco âmbitos, a saber: a sustentabilidade, a conectividade e a sensorização, o sistema de informação e a inovação (INVATTUR, 2015). Nesta perspectiva este mesmo modelo favorece, também, a aplicação dos princípios da sustentabilidade ao apostar na melhoria do capital humano e social, na configuração de destinos mais acessíveis, seja do ponto de vista físico ou digital, bem como em fatores como a melhoria da mobilidade, da eficiência energética, da reutilização da água, do tratamento de resíduos sólidos, da infraestrutura em geral, entre outros aspectos para os quais o uso das novas tecnologias contribuem diretamente e que, por conseguinte, potencializam o desenvolvimento sustentável e integrado, impactando melhoria da imagem e no posicionamento dos destinos (IVATTUR, 2015). A partir deste panorama foram analisadas as contribuições participativas relacionadas ao eixo estratégico "governança e sustentabilidade» contidas no plano, buscando observar o entendimento, as convergências e divergências destas contribuições para o processo de planejamento, conforme o gráfico 1. De partida, observa-se que a visão de futuro proposta contempla as principais demandas apresentadas pelos atores do processo, desde aquelas relacionadas diretamente à gestão do destino expressas pelas categorias "Instâncias de Governança Regionais e Municipais fortalecidas», «Instrumentos de planejamento turísticos implantados» e «Sociedade sensibilizada para o turismo", sendo estas as três categorias mais citadas pelos participantes (tanto das oficinas regionais, quanto dos grupos focais), até outras que também impactam a gestão do destino, mas podem ser entendidas como questões mais amplas e estruturais como o caso das categorias: «Capital humano e lideranças qualificadas» e "Parcerias público-privadas efetivadas» que juntas integram a visão de futuro proposta: ser «destino turístico de qualidade, inteligente e inovador», "alicerçado no capital humano qualificado» 
Actas del Seminario Internacional Destinos Turísticos Inteligentes:

nuevos horizontes en la investigación y gestión del turismo

Universidad de Alicante, 26 y 27 de octubre de 2017

com uma "modernização pública e privada» e uma "governança colaborativa e pactuada pelos atores locais" posicionando o turismo como atividade «promotora da qualidade de vida de seus habitantes».

Gráfico 1. Principais categorias relacionadas à «Governança e Sustentabilidade»

Eixo: Governança e Sustentabilidade

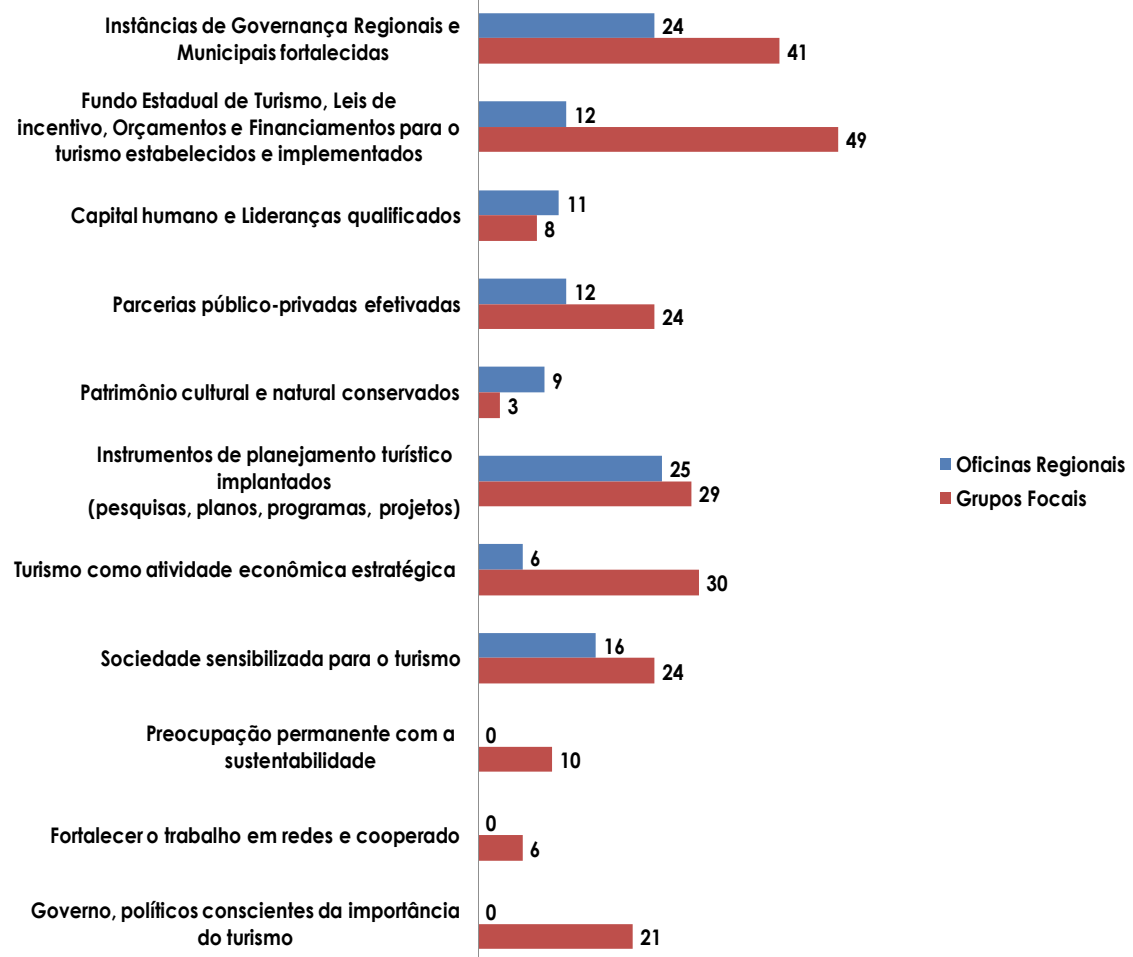

Fonte: os autores, adaptado de CEPATUR (2016, p. 93).

Entretanto, quando se observa individualmente cada categoria é possível identificar outras demandas em comum expressas, quantitativamente, de forma diferenciada pelos participantes. Neste sentido chama à atenção o fato dos grupos focais, formado pelo setor privado, apresentarem com expressividade temas relacionados diretamente à atuação pública como a disponibilidade de "fundo estadual de turismo (...) e incentivos» e a 
Actas del Seminario Internacional Destinos Turísticos Inteligentes:

nuevos horizontes en la investigación y gestión del turismo

Universidad de Alicante, 26 y 27 de octubre de 2017

percepção da necessidade de maior compromisso do setor público com a atividade quando indicam "governos e políticos conscientes da importância do turismo». Também fica evidenciado o fato de que os grupos focais destacaram mais a necessidade de um melhor posicionamento do «turismo como atividade econômica estratégica » para o Paraná, uma vez que esta categoria aparece com grande expressividade. A mesma também aparece nas oficinas regionais, mas com menor expressividade, apontando para o papel do plano como um instrumento que busque potencializar este aspecto e apresente estratégias que facilite a integração institucional, público e privada (tema que também é evidenciado nas contribuições participativas e contemplado na visão de futuro) para ativar o papel estratégico da atividade turística na economia do Estado.

De maneira geral as contribuições participativas para o eixo «governança e sustentabilidade» mais convergem para os conceitos dos mesmos, conforme explicitado anteriormente, do que divergem, uma vez que os resultados tendem mais a se aproximar dos conceitos (que por natureza são polissêmicos), que se distanciarem e tocam nos pontos chaves dos mesmos, como aspectos institucionais da governança, a implementação de instrumentos de planejamento e desenvolvimento, a existência de um capital humano qualificado, as parcerias público-privadas, a preocupação com a sustentabilidade, o fortalecimento do trabalho em redes e cooperado es governos mais conscientes da importância do turismo. Mesmo que estes três últimos temas tenham aparecido mais explicitamente somente nos grupos focais é representativo da demanda do trade turístico e apontam para as expectativas que os atores do território possuem sobre a efetividade do processo de planejamento em curso. Assim, mesmo não conhecendo o conceito DTI, os resultados, ainda que de modo genérico, convergem elementos que caracterizam o modelo DTI sendo estes pontos que devem estar presentes quando se pensa na conformação deste modelo. Entretanto, um item a ser melhor abordado no processo é como o uso e gestão das TIC são importantes para gerar conhecimento e subsidiar processos de tomada de decisões para o destino (INVATTUR, 2015; Manente, 2008). Propostas relacionadas à sustentabilidade, elemento chave no modelo DTI, também aparecem nas contribuições dos participantes quando apontam para a necessidade do cuidado com o patrimônio natural e cultural, de uma sociedade sensibilizada para o turismo, de um capital humano qualificado e da consciência política sobre a importância estratégica atividade turística. 
Actas del Seminario Internacional Destinos Turísticos Inteligentes: nuevos horizontes en la investigación y gestión del turismo

Universidad de Alicante, 26 y 27 de octubre de 2017

Modernizar a gestão contando com uma estrutura tecnológica e organizacional de vanguarda, com permanente compartilhamento de informações, modernizando a gestão pública e privada, incentivando parcerias e criando um ambiente positivo para negócios, tendo a descentralização e a regionalização como base, assim como a criação de um fundo estadual de turismo e a institucionalização de incentivos, fomento e linhas de financiamento; garantindo o desenvolvimento de forma sustentável e responsável (CEPATUR, 2016, p. 98).

Percebe-se que o pacto proposto, no que tange aos aspectos de governança e sustentabilidade, expõe o compromisso de operacionalizar as contribuições propostas pelos atores como a modernização da gestão, a descentralização e regionalização como base para o planejamento, a criação de um Fundo Estadual de Turismo, como mecanismo que permita viabilizar maiores investimentos e a implementação de planos e projetos (demanda destacada pelos participantes), além da preocupação com a sustentabilidade do processo.

\subsection{Qualidade e Competitividade}

Como as cidades estão em contínua transformação, o planejamento urbano constitui-se em atividade que se estenderá ao longo do tempo, e assim, a inovação é fonte de vantagem competitiva para as empresas e destinos turísticos (Hjalager, 2000; Ritchie \& Crouch, 1993). Para Sainaghi, Phillips \& Zavarrone (2017), o turismo, que é atrelado a globalização, governos, negócios e sociedade, precisa de novas formas de pensamento estratégico, até porque a concorrência entre destinos continua a se intensificar (Bornhorst, Ritchie \& Sheehan, 2010, citados por Sainaghi, et al., 2017, p. 38). Uma forma de concretizar tais pensamentos é através de políticas públicas. A qualidade destas dependem das características do processo político que, por sua vez, é determinado por fatores culturais, padrões de comportamento político e, inclusive, atitudes singulares de atores políticos (Frey, 2000). Neste contexto, é possível delimitar que algumas das categorias citadas no plano dependem exclusivamente da gestão e abrangem as categorias citadas da qualificação profissional para o setor, o fortalecimento da iniciativa privada e o bom relacionamento das parcerias público-privadas para que os processos de normalização e certificação em turismo possam ser implantados com responsabilidade, apresentando os resultados desejados em 2026, conforme demonstrado no gráfico 2 . 
Actas del Seminario Internacional Destinos Turísticos Inteligentes:

nuevos horizontes en la investigación y gestión del turismo

Universidad de Alicante, 26 y 27 de octubre de 2017

Gráfico 2. Principais categorias relacionadas à «Qualidade e Competitividade»

Eixo: Qualidade e Competitividade

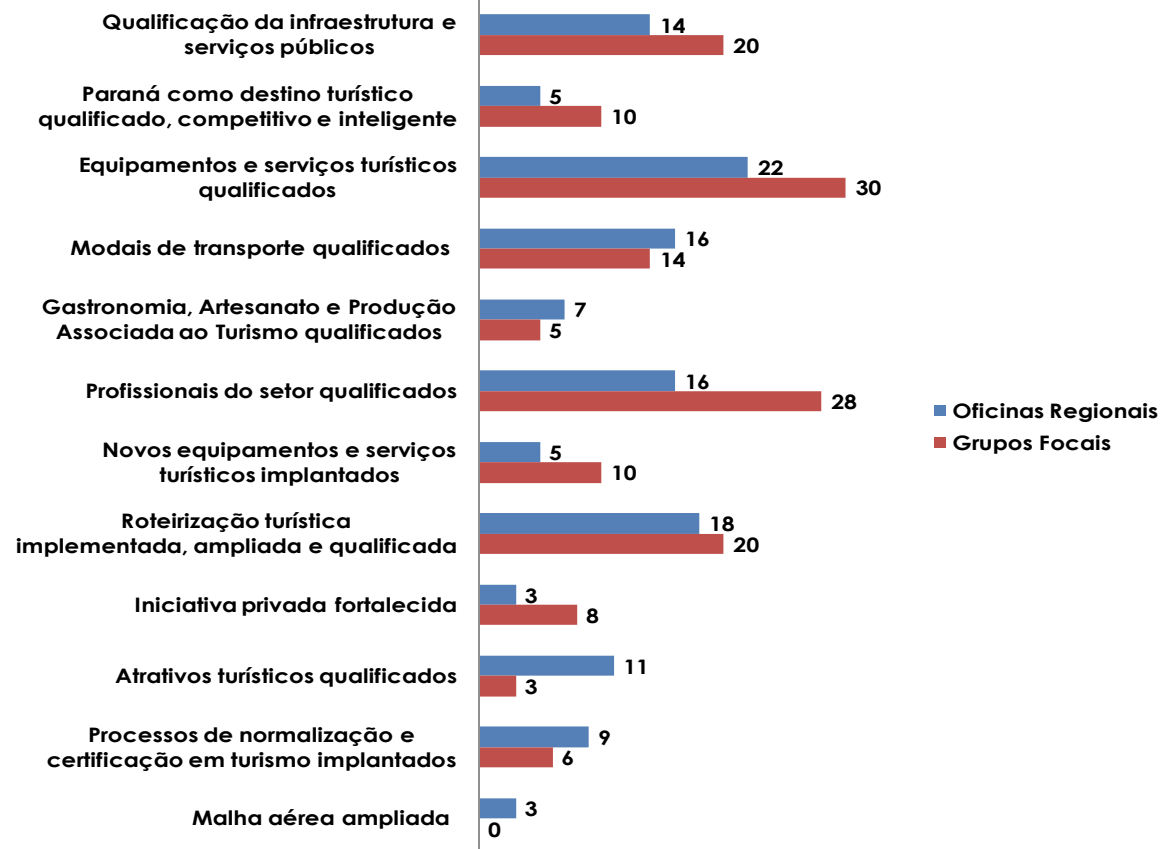

Fonte: os autores, adaptado de CEPATUR (2016, p. 94).

As principais menções das contribuições participativas foram: equipamentos e serviços turísticos qualificados; profissionais do setor qualificados; qualificação da infraestrutura e serviços públicos, e; roteirização turística implementada, ampliada e qualificada (CEPATUR, 2016). Assim, para Flores \& Mendes (2014), na visão integrada do destino turístico, observa-se o destino como um sistema onde o turista vivenciará a sua experiência, cujo conteúdo é co-criado através de cooperação e redes de empresas públicas e privadas para a realização de uma experiência de excelência. E para Mendes (2004), o destino turístico deverá ser suportado por uma estrutura de gestão que lidere e assegure a direção do desenvolvimento turístico na região: gerando recursos; coordenando o trabalho em conjunto das diferentes partes do sistema; e estabelecendo objetivos e estratégias, que permitam ao destino competir mais eficazmente. 
Actas del Seminario Internacional Destinos Turísticos Inteligentes: nuevos horizontes en la investigación y gestión del turismo

Universidad de Alicante, 26 y 27 de octubre de 2017

A implantação e qualificação dos equipamentos e serviços turísticos, bem como a qualificação dos modais de transportes, da gastronomia, o artesanato e da produção associada ao Turismo, são categorias apontadas no plano e que expressam a necessidade de melhorias para o mercado turístico do Paraná. Deste modo, o turismo necessita de decisões e ações políticas para movimentar o terceiro setor da economia e para mobilizar a gestão urbana já que a estrutura urbana dimensiona o sucesso ou o insucesso de um destino turístico. Goeldner, Ritchie \& McIntosch (2002) entendem como política pública para o turismo o conjunto de regulamentações, regras, diretrizes, diretivas, objetivos e estratégias de desenvolvimento e promoção que fornece uma estrutura na qual são tomadas as decisões coletivas e individuais que afetam diretamente o desenvolvimento turístico e as atividades diárias dentro de uma destinação. Sobre a capacitação do trade turístico, Richie \& Crouch, 2005 (citado por Boes, Buhalis \& Inversini, 2015, p. 393) citam que para se garantir o sucesso de um destino turístico, este deve estar aliado aos recursos humanos e inovação através de mútua cooperação local e regional. Além disso, uma liderança coordenada e em rede é essencial (Zehrer, Raich, Siller et al., 2014). Quanto a qualificação da infraestrutura e de serviços públicos, a partir da decisão do turista é requerido um conjunto de condições que inclui a própria infraestrutura (aeroportos, telecomunicações, etc.), serviços de acomodação (hotéis, locais para camping, etc.), fornecimento alimentício (restaurantes, pubs, etc.), serviços de entretenimento (shoppings, museus, etc.) e serviços receptivos (agências de viagens, serviços de informação, guias, etc.) necessários para a efetivação da viagem (Smith, 1994, citado por Hjalager, 2000, p. 202) e para a sua atratividade (Calvo-Mora, Berbel-Pineda, Periáñez, et al., 2011). Portanto, os envolvidos no plano Paraná Turístico 2026 pactuam que a qualidade e competitividade do destino Paraná deverão:

Integrar visitantes e visitados através da cultura da hospitalidade, resultando em co-criação de valor, enfatizando os aspectos naturais e culturais, maximizando a qualidade das experiências dos visitantes, ao contar com atrativos, infraestruturas, equipamentos e serviços de excelência; ressaltando elementos de diferenciação, contando com uma imagem e reputação positivas, fortalecendo o posicionamento e a marca desejados, inovando permanentemente com o auxílio das tecnologias da informação e comunicação (CEPATUR, 2016, p. 98). 
Actas del Seminario Internacional Destinos Turísticos Inteligentes: nuevos horizontes en la investigación y gestión del turismo

Universidad de Alicante, 26 y 27 de octubre de 2017

\subsection{Marketing e Inovação}

Com relação ao Marketing e Inovação, o plano pretende:

Desenvolver ações de marketing inovadoras, integradas e interativas, contando com o apoio das tecnologias da informação e comunicação na conformação de produtos e serviços, assim como, na promoção e comercialização dos mesmos, considerando estrategicamente os produtos mais competitivos para os segmentos mais atrativos, gerando vendas e consumo de forma ética; inovando tanto no planejamento e gestão de aspectos como organização e processos dos produtos e serviços, quanto no marketing dos mesmos (CEPATUR, 2016, p. 98).

Para a SEGITTUR, uma inovação é a introdução de um produto, seja ele bem, serviço ou de um processo, novo ou melhorado, ou a introdução de um método novo de comercialização ou organização aplicado às práticas de negócio, a organização do trabalho ou às relações externas. Classificam-se em quatro tipos: 1) Inovação de produtos: bem ou serviço novo ou melhorado nas especificações técnicas, como componentes ou materiais, o software incorporado, a ergonomia e outras características funcionais; 2) Inovação de processo: inclui melhoria técnica, de equipamento ou de software. 3) Inovação comercial: novo método de comercialização que agregue melhoria no desenho ou apresentação do produto, seu posicionamento ou seu preço; 4) Inovações organizacionais: novo método de organização aplicado às práticas de negócio, organização do trabalho ou as relações externas da empresa (SEGITTUR, 2014, p. 51). A inovação, por meio de seu conceito amplo, é majoritariamente incluída nas definições sobre destino inteligente (Blanco, 2015; Ivars Baidal, Solsona Monzonís \& Giner Sánchez, 2015; Luque Gil, Zayas Fernández, Caro Herrero, 2015; Micera, Presenza, Splendiani, et al., 2013, citado por Fermenia-Serra \& Perea-Medina, 2016; Navarro-Jurado, 2016; SEGITTUR, 2015; Vergara \& Rivas, 2004) e sua incorporação não pode limitar-se a um momento pontual: deve-se promover a inclusão de processos inovadores de maneira contínua assimilando a inovação como uma transformação permanente que deverá contar com metodologias adequadas e provadas (Blanco, 2015, p. 122). Contudo, para Hjalager (2010), o conhecimento empírico é muito limitado sobre os efeitos da inovação tanto em empresas quanto em destinos turísticos.

Quanto ao marketing, certo é que a competitividade entre os destinos tem aumentado, notadamente, pelo compartilhamento de opiniões nas 
Actas del Seminario Internacional Destinos Turísticos Inteligentes: nuevos horizontes en la investigación y gestión del turismo

Universidad de Alicante, 26 y 27 de octubre de 2017

redes sociais, sendo a internet essencial na midiatização do turismo (Middleton \& Clarke, 2002; Richards, 2009), bem como canal de promoção e divulgação turística e de comunicação entre o trade turístico e instâncias de governança com o turista (Buhalis \& Law, 2008). Durante o processo de pesquisa de (Gretzel, Werthner, Koo, et al., 2015), observou-se que o marketing digital, principalmente o marketing de mídia, redes sociais e de busca pode desempenhar papel muito importante na promoção turística online e por esse motivo, as organizações públicas e privadas de turismo devem estar atentas a adotar e realizar tais estratégias. Buhalis (2000) ainda defende que o marketing dos destinos deve balancear os objetivos estratégicos de todas as partes envolvidas com a sustentabilidade dos recursos locais, além de diferenciar seus produtos e desenvolver parcerias público-privadas. No que tange às principais categorias identificadas nas oficinas regionais e grupos focais, quinze foram relacionadas (CEPATUR, 2016, p. 95), conforme identificadas no gráfico 3.Os entrevistados foram unânimes em atribuir a adoção de "ações inovadoras de promoção e comercialização desenvolvidas permanentemente» como prioridade para visualização do Paraná como DTI, seguido do uso ampliado das tecnologias de informação para o turismo; produtos turísticos inovadores; ampliação da promoção turística e sites e portais de turismo com qualidade (CEPATUR, 2016). Os territórios inteligentes priorizam a inovação e o empreendedorismo, uma vez que melhoram a competitividade do destino (Caragliu, Del Bo \& Nijkamp, 2011), e isto posto, os promotores de turismo devem estar abertos a toda e qualquer tipo de inovação se desejarem chegar ao turista atual, especialmente se for inerente à tecnologia. Ao mesmo tempo, observa-se que, porquanto a ampliação da promoção turística tenha figurado como a segunda categoria mais citada pelos grupos focais, o uso ampliado das tecnologias de informação para o turismo situa-se no segundo lugar para as oficinas regionais. Cidades inteligentes utilizam a TIC em seus processos de produção (Giffinger, 2007) para coletar e integrar os dados a permitir um melhor uso da infraestrutura física e de outros recursos (Koo, Gretzel, Hunter, et al., 2015), como melhorar a qualidade de vida do cidadão (Piro, Cianci, Grieco et al., 2014). Estes conceitos podem ser diretamente aplicados a destinos turísticos (Gretzel, Werthner, Koo, et al., 2015), uma vez que cresce a ideia de que um destino inteligente deriva de uma cidade inteligente (Guo, Liu \& Chai, 2014; Luque Gil, Zayas Fernández \& Caro Herrero, 2015; Tu \& Liu, 2014). Os destinos inovadores, consolidados em infraestrutura tecnológica que garante o desenvolvimento 
sustentável do território, acessível, que facilita a interação e a integração dos visitantes com o entorno incrementam a qualidade da experiência no destino (Boes, Borde \& Egger, 2015; Lamsfus, Martín, Alzua-Sorzabal \& Torres-Manzanera, 2015; SEGITTUR, 2015).

No tocante à ampliação da promoção turística, temos a visão de Buhalis (2000) que dita que é necessário tirar vantagem das novas tecnologias, bem como da internet, para melhorar a competitividade dos destinos

Gráfico 3. Principais categorias relacionadas ao eixo «Marketing e Inovação»

Eixo: Marketing e Inovação

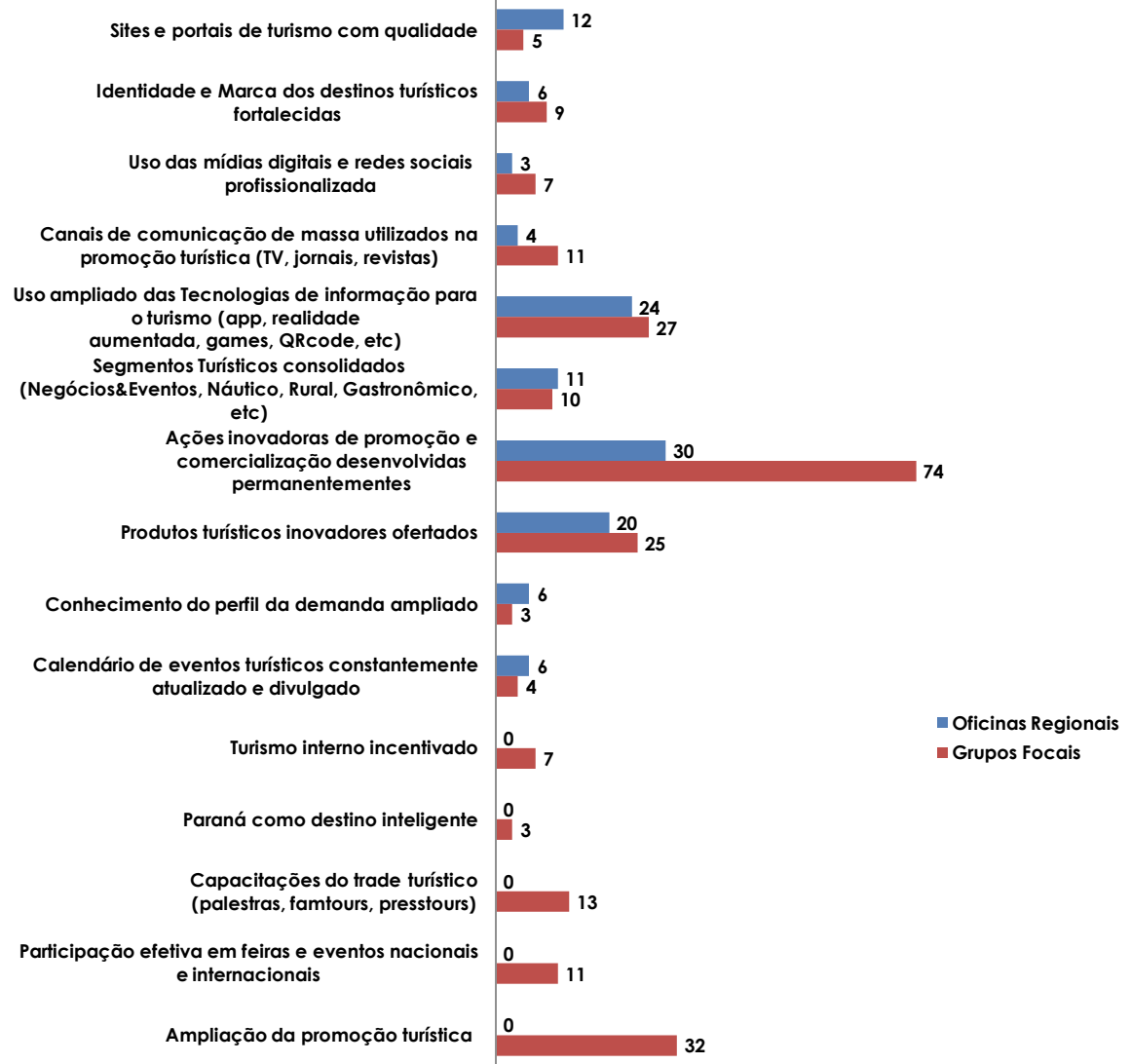

Fonte: os autores, adaptado de CEPATUR (2016, p. 95). 
Actas del Seminario Internacional Destinos Turísticos Inteligentes:

nuevos horizontes en la investigación y gestión del turismo

Universidad de Alicante, 26 y 27 de octubre de 2017

aumentando assim sua visibilidade, reduzindo custos e melhorando a cooperação local, ou seja, é necessário utilizar inovações para que o marketing do destino alcance o maior número de pessoas.

Para os grupos focais o terceiro lugar pertence ao uso ampliado das TIC, já descrito, porquanto para as oficinas regionais o posto concerne aos produtos turísticos inovadores ofertados. Diretamente aos turistas, os produtos ou serviços inovadores são percebidos como uma extensão que pode vir a ser um fator de decisão da compra (Hjalager, 2010). Sobre a última posição de ambos os grupos, as situações são curiosas. Demonstrou-se haver pouca relevância, para as oficinas regionais, da utilização das mídias digitais e redes sociais de forma profissionalizada, ignorando que os turistas têm se tornado mais independentes e sofisticados, utilizando as mais variadas ferramentas quando da organização de suas viagens, e isso inclui consulta a redes sociais e portais na internet Buhalis \& Law (2008). Ainda com relação aos grupos focais, verificar o perfil da demanda ampliado é o menos mencionado, conjuntamente com a categoria Paraná como destino inteligente. No entanto, para Buhalis (2000), entender os tipos de destino e suas características é de suma importância para sua comercialização, e, deste modo, os atores do Turismo devem observar as justificativas de viagem para desenvolver atividades adequadas ao perfil do mercado-alvo. Quanto a categoria Paraná como destino inteligente, precisamos lembrar que aversão a riscos, resistência a mudanças e baixa consciência sobre a importância de inovações são algumas das barreiras enfrentadas por toda a indústria do turismo (Janoska \& Kopera, 2014) e o nível de risco associado ao desenvolvimento de inovação aumenta quando o meio apresenta condições voláteis e instáveis (Du Cluzeau, 2006, Dwyer \& Edwards, 2009 citado por Janoska \& Kopera, 2014), especialmente em período de recessão ${ }^{5}$.

\section{Considerações finais}

A preocupação em transformar os destinos em localidades que gerem maior satisfação e valor agregado aos seus visitantes, que diminuam os custos e acrescentem outras vantagens, motivou os atores públicos e privados relacionados ao planejamento e gestão desses, bem como a sociedade civil e

5. Brasil. (2017). Ministério da Fazenda. Brasil está voltando à normalidade econômica e política, diz Meirelles. Disponível em: <www.fazenda.gov.br/noticias/2017/marco/brasil-esta-voltando-a-normalidade-economica-e-politica-diz-meirelles>. 
Actas del Seminario Internacional Destinos Turísticos Inteligentes: nuevos horizontes en la investigación y gestión del turismo

Universidad de Alicante, 26 y 27 de octubre de 2017

academia a se mobilizarem para fins de criação do plano estratégico «Paraná Turístico 2026: Pacto para um Destino Inteligente».

$\mathrm{O}$ trabalho analisou as contribuições participativas relacionadas aos três eixos estratégicos do plano e pode-se apreender que as mesmas influenciaram e subsidiaram a definição da visão de futuro e pacto institucional expressos no documento, imprimindo legitimidade ao processo e respaldo da participação social para o planejamento estratégico, uma vez que se trata de um documento direcionador de longo prazo. Considerando que tanto a "governança e sustentabilidade» constituem pilares para uma boa gestão de destinos turísticos, sendo características e práticas a serem buscadas, inventadas e reinventadas constantemente, faz-se necessário repensar a forma de se fazer política pública e gestão que sejam capazes de assimilar a demanda da participação social e, também, assumir os novos desafios, articular amplas parcerias, viabilizar e dispor de recursos, humanos, materiais e financeiros para consolidar as estratégias desenhadas, de forma a fazer avançar e consolidar o futuro que se almeja. Dentre os macroprogramas previstos para que se alcancem os objetivos do plano vinculados aos eixos "qualidade e competitividade» estão a modernização da gestão, a inovação e competitividade da oferta turística e o Destino Turístico Inteligente que aliam o papel fundamental da gestão em todos estes processos e consistem no envolvimento e estímulo de órgãos públicos e privados para que a atividade se fortaleça sem prejudicar outras estruturas e a comunidade, pois, o turismo, de forma organizada e sustentável, não deve ser um fator negativo para a localidade, mas um forte gerador de benefícios para o estado, população e instituições públicas e privadas. Ademais, uma iniciativa a longo prazo (10 anos) também instiga, de certa forma, esperança de que as ações serão tomadas e mantidas com maior seriedade e comprometimento pelos envolvidos e por este motivo que os grupos pesquisados (oficinas regionais e grupos focais) foram unânimes em atribuir a "Ações inovadoras de promoção e comercialização desenvolvidas permanentemente» como a categoria de maior importância no eixo "marketing e inovação».

Nesta perspectiva, sendo os destinos turísticos lugares dinâmicos e que demandam constante gestão, é importante pontuar que, qualquer processo de planejamento, bem como os documentos que os expressam, devem possuir clareza e capacidade de apontar para uma ambição consensual e dinâmica de onde se pretende chegar, animada por uma visão, objetivos e estratégias que orientem, mas que não sejam estanques, permitindo 
Actas del Seminario Internacional Destinos Turísticos Inteligentes:

nuevos horizontes en la investigación y gestión del turismo

Universidad de Alicante, 26 y 27 de octubre de 2017

ajustar-se à um mercado em constante mudanças e, também, adaptar-se às tendências atuais e tais características foram possíveis de serem observadas no documento analisado. Dessa maneira, as contribuições levantadas alimentaram o processo metodológico da participação social, mesclado ao planejamento estratégico, funcionando como fonte de informações que deverão contribuir para o sucesso da implementação do plano, permitindo alcançar maior grau de cooperação, consenso e comprometimento dos atores dos destinos. Os resultados apontam para a convergência conceitual relacionada ao modelo DTI e reforçam a importância da visão sistêmica e o senso de pertencimento dos atores participantes no sentido de dar maior sustentação ao desenvolvimento pretendido. Contudo, é importante destacar que a gestão de destinos não se encerra com a elaboração de uma estratégia ou um plano, mas parte daí para, de forma pactuada e inteligente, ativar atores, instituições e capacidades que transforme as estratégias em realidade e avance rumo ao que se espera, de forma contínua e com visão de processo de curto, médio e longo prazos.

\section{Referências}

Ávila Muñoz, A. L. \& García Sánchez, S. (2013). Destinos turísticos inteligentes. Harvard Deusto Business Review, 224, 56-67.

Bac Lija, I. (2013). Reconceptualisation of urban management: evidence from EU cities. Theoretical and Empirical Researches in Urban Management, 8(1), 30-50.

Bardin, I. (1994). Análise de conteúdo. Lisboa: Edições Setenta.

Barrado Timón, D. A. (2004). El concepto de Destino Turístico - Una aproximación geográfico-territorial. Estudios Turísticos, 160, 45-68.

Blanco, J. (2015). Libro blanco de los destinos turísticos inteligentes: estratégias y soluciones para fomentar la innovación em el turismo digital. Madrid, Espanha: LID Editorial Empresarial.

Blanco, I. \& Gomá, R. (2003). Gobiernos locales y redes participativas: retos e innovaciones. Revista del CLAD Reforma y Democracia, 26, 1-15.

Boes, K.; Borde, L. \& Egger, R. (2015). The Acceptance of NFC Smart Posters in Tourism. In: Tussyadiah, I. \& Inversini, A. (Eds.). Information and Communication Technologies in Tourism 2015. Heidelberg: Springer, 435-448.

Boes, K., Buhalis, D. \& Inversini, A. (2015). Conceptualising Smart Tourism Destination Dimensions. In: Tussyadiah, I. \& Inversini, A. (Eds.). Information and Communication Technologies in Tourism 2015. Heidelberg: Springer, 391-403.

Buhalis, D. (2000). Marketing the competitive destination of the future. Tourism Management, 97-116. 
Actas del Seminario Internacional Destinos Turísticos Inteligentes:

nuevos horizontes en la investigación y gestión del turismo

Universidad de Alicante, 26 y 27 de octubre de 2017

Buhalis, D. \& Amaranggana, A. (2014). Smart tourism destinations. In: Xiang, Z. \& Tussyadiah, I. (Eds.). Information and Communication Technologies in Tourism 2014. Heidelberg: Springer, 553-564.

Buhalis, D. \& Law, R. (2008). Progress in information technology and tourism management: 20 years on and 10 years after the Internet. Tourism Management, 29, 609-623.

Butler, R.W. (1999). Sustainable tourism - a state of art review. Tourism Geographies: an international journal of tourism space, place and environment. Florence, 1(1), 7-25.

Calvo-Mora, A.; Berbel-Pineda, J. M.; Periáñez, R. \& Suárez, E. M. (2011).

Determining factors of a city's tourism attractiveness. Tourism \& Management Studies, 7, 9-23.

Caragliu, A.; Del Bo, C. \& Nijkamp, P. (2011). Smart cities in Europe. Journal of Urban Technology, 18, 65-82.

Castells, M. (1999). A Era da informação: economia, sociedade e cultura. São Paulo: Paz e terra.

CEPATUR - Conselho Paranaense de Turismo. (2016). Paraná Turístico 2026 - Pacto para um destino inteligente. Disponível em: <www.turismo.pr.gov.br/arquivos/ File/institucional/PLANO_DE_TURISMO/ParanaTuristico2026documentocompleto__1.pdf >

Creswell, J. (2010). Projeto de pesquisa: métodos qualitativo, quantitativo e misto. Porto Alegre: Artmed.

Dencker, A. F. M. (2007). Pesquisa em Turismo: planejamento, métodos e técnicas. São Paulo: Futura.

Ejarque, J. (2005). Destinos turísticos de êxito: Desenho, criação, gestão e marketing. Madrid: Pirámide.

Farinós, J. (2008). Gobernanza territorial para el desarrollo sostenible: estado de la cuestión y agenda. Boletín de la Asociación de Geógrafos Españoles, 46, 11-32.

Femenia Serra, F. \& Perea Medina, M. J. (2016). Analysis of three Spanish potential smart tourism destinations. In: 6th International Conference on Tourism - New Challenges and boundaries in tourism: policies, innovations and strategies. Nápoles, IT.

Flores, L. C. da S. \& Mendes, J. da C. (2014). Perspectivas do destino turístico: repensando o sentido do conceito. Revista Brasileira de Pesquisa em Turismo, 222237.

Framke, W. (2002). The Destination as a Concept: A Discussion of the Business-related Perspective versus the Socio-cultural Approach in Tourism Theory. Scandinavian Journal of Hospitality and Tourism, 92-108. 
Actas del Seminario Internacional Destinos Turísticos Inteligentes:

nuevos horizontes en la investigación y gestión del turismo

Universidad de Alicante, 26 y 27 de octubre de 2017

Frey, K. (2000). Políticas públicas: um debate conceitual e reflexões referentes à prática da análise de políticas públicas no Brasil. Planejamento e Políticas Públicas. Brasília: IPEA, 21, 211-259.

Getz, D. \& Jamal, T. B. (1994). The environment-community symbiosis: a case for collaborative tourism planning. Journal of Sustainable Tourism, 2, 152-173.

Giffinger, R. (2007). Smart Cities - Ranking of European medium-sized cities. Vienna: Centre of Regional Science.

Goeldner, C.R.; Ritchie, J. R. B. \& McIntosch, R.W. (2002). Turismo: princípios, práticas e filosofias. Porto Alegre: Bookman.

Graziano, T. (2014). Boosting innovation and development: the italian smart tourism, a critical perspective. European Journal of Geography, 5(4), 6-18.

Gretzel, U., Sigala, M.; Xiang, Z. \& Koo, C. (2015). Smart tourism: foundations and developments. Eletronic Markets, 25, 179-188.

Gretzel, U.; Werthner, H.; Koo, C. \& Lamsfus, C. F. (2015). Conceptual foundations for understanding smart tourism ecosystems. Computers in Human Behavior, 50, 558-563.

Guo, Y.; Liu, H. \& Chai, Y. (2014). The embedding convergence of smart cities and tourism internet of things in China: An advance perspective. Advances in Hospitality and Tourism Research, 2(1), 54-69.

Hall, C. M. (2001). Planejamento Turístico: políticas, processos e planejamentos. São Paulo: Contexto.

- (2011). A typology of governance and its implications for tourism policy analysis. Journal of sustainable tourism, 19(4-5), 437-457.

Hjalager, A. M. (2000). Tourism Destinations and the Concept of Industrial Districts. Tourism and hospitality research, 2(3), 199-213.

- (2010). A review of innovation research in tourism. Tourism Management, 31, 1-12.

INVAT-TUR - Agència Valenciana del Turisme. (2015). Destinos Turísticos Inteligentes. Disponível em: <http://pt.slideshare.net/invattur/manual-operativo-para-la-configuracin-de-destinos-inteligentes $>$.

Irving, M. A.; Bursztyn, I.; Sancho, A. P. \& Melo, G.M. (2005). Revisitando significados em sustentabilidade no planejamento turístico. Caderno Virtual de Turismo: Instituto Virtual de Turismo. Rio de Janeiro, 18, 1-7.

Ivars Baidal, J.A.; Rodríguez Sánchez, I.; Vera Rebollo, J. F. \& Acebal, A. (2014). Nuevos enfoques en gestión turística: el programa de agrupaciones empresariales innovadoras en España. Boletín de la Asociación de Geógrafos Españoles, 66(1), 369-395.

Ivars Baidal, J. A.; Solsona Monzonís, F. J. \& Giner Sánchez, D. (2016). Gestión turística y tecnologías de la información y la comunicación (TIC): El nuevo enfoque de los destinos inteligentes. Documents d'Anàlisi Geogràfica, 62(2), 327-346. 
Actas del Seminario Internacional Destinos Turísticos Inteligentes:

nuevos horizontes en la investigación y gestión del turismo

Universidad de Alicante, 26 y 27 de octubre de 2017

Janoska, M. N. \& Kopera, S. (2014). Exploring barriers to innovation in tourism industry - the case of southern region of Poland. Procedia - Social and Behavioral Sciences, 110, 190-201.

Jiang, H. (2013). The research review of intelligent tourism. Journal of Management and Strategy, 4(4), 65-67.

Jovicic, D. Z. (2016). Key issues in the conceptualization of tourism destinations. Tourism Geographies, 445-457.

Koo, C.; Gretzel, U.; Hunter, W. C. \& Chung, N. (2015). The role of IT in tourism. Asia Pacific Journal of Information Systems, 25(1), 99-104.

Lamsfus, C.; Martín, D.; Alzua-Sorzabal, A. \& Torres-Manzanera, E. (2015). Smart tourism destinations: An extended conception of smart cities focusing on human mobility. In: Tussyadiah, I. \& Inversini, A. (Eds.). Information and Communication Technologies in Tourism 2015. Heidelberg: Springer, 363-375.

Luque Gil, A. M.; Zayas Fernández, B. \& Caro Herrero, J. L. (2015). Los Destinos Turísticos Inteligentes en el marco de la Inteligencia Territorial: conflictos y oportunidades. Investigaciones Turísticas, 10, 1-25.

Manente, M. (2008). Destination Management and Economic Backgorund. Defining and monitoring local tourist destinations. In: International Conference of Tourism, Málaga, 2008. Disponível em: <http://statistics.unwto.org/sites/all/files/ pdf/manente_eng_0.pdf >.

Mendes, J.C. (2004). Gestão da qualidade nos destinos turísticos: o caso português. Tese doutoramento. Universidade do Algarve, Faculdade de Economia. Faro, Portugal.

Middleton, V. T. C. \& Clarke, J. (2002). Marketing de turismo: teoria e prática. Rio de Janeiro: Campus.

MTUR -Ministério do Turismo. (2016). Estudo da Demanda Turística Internacional 2015. Disponível em: <www.dadosefatos.turismo.gov.br/2016-02-04-11-54-03/ demanda-tur\%C3\%ADstica-internacional.html>

Nam, T. \& Pardo, T. A. (2011). Conceptualizing smart city with dimensions of technology, people, and institutions. In: The Proceedings of the 12th Annual International Conference on Digital Government Research, College Park, MD, USA, 282-291.

Navarro-Jurado, E. (2016). Medición y evaluación de la sostenibilidad a través de indicadores. El caso de Andalucía. In: Congreso Turismo de la UJI 2016, Castellón, ES.

Paraná Turismo. (2014). Paraná - Estudo Estatístico 20 anos de Turismo. Disponível em: <www.turismo.pr.gov.br/arquivos/File/Parana_Estudo_Estatistico_20_ anos_Turismo__1.pdf>

Pearce, D. G. (2014). Toward an Integrative Conceptual Framework of Destinations. Journal of Travel Research, 53(2), 141-153. 
Actas del Seminario Internacional Destinos Turísticos Inteligentes:

nuevos horizontes en la investigación y gestión del turismo

Universidad de Alicante, 26 y 27 de octubre de 2017

- (2015). Destination management in New Zealand: Structures and functions. Journal of Destination Marketing \& Management, 4(1), 1-12.

- (2016). Modelos de gestión de destinos: Síntesis y evaluación. Estudios en Turismo, 25(1), 1-16.

Perez, C. (2010). Revoluciones tecnológicas y paradigmas tecno-económico. Cambridge Journal of Economics, 34(1), 185-202.

Piro, G.; Cianci, I.; Grieco, L. A.; Boggia, G. \& Camarda, P. (2014). Information centric services in smart cities. The Journal of Systems and Software, 88, 169-188.

PNUD - Programa das Nações Unidas para o Desenvolvimento. (1996). Our Global Neighborhood Report of the Commission on Global Governance. Disponível em: <www.gdrc.org/u-gov/global-neighbourhood/chap1.htm>

Pulido, M. C. \& Pulido, J. I. (2013). Destinos turísticos: conformación y modelos de gobernanza. In: Pulido J. I. \& Cárdenas P. J. (coord.): Estructura economica de los mercados turisticos. Madrid: Síntesis, Madrid, 179-204.

- (2014). ¿Existe gobernanza en la actual gestión de los destinos turísticos? Estudio de casos. Pasos: Revista de Turismo y Patrimonio Cultural, 12(4), 685-705.

Rezende, D. A. (2012). Planejamento de estratégias e informações municipais para cidade digital: guia para projetos em prefeituras e organizações públicas. São Paulo: Brasil: Atlas.

Rezende, D. A. \& Castor, B. V. (2005). Planejamento estratégico municipal: empreendedorismo participativo nas cidades, prefeituras e organizações públicas. Rio de Janeiro: Brasport.

Richards, G. (2009). Turismo cultural: padrões e implicações. In: Camargo, P. \& Cruz, G. da (Orgs.). Turismo cultural: estratégias, sustentabilidade e tendências. Ilhéus: Editus, 25-48.

Ritchie, J.R.B. \& Crouch, G.I. (1993). Competitiveness in International Tourism - a Framework for Understanding and Analysis. 43rd Congress of the Association International d'Experts Scientifiques du Tourisme, San Carlos de Bariloche, Argentina, 17-23.

Rosenau, J. N. (2000). Governança, ordem e transformação na política mundial. In: Rosenau, J. N. \& Czempiel, E. (Orgs.). Governança sem governo: ordem e transformação na política mundial. Brasília: UNB, 11-46.

Sainaghi R.; Phillips, P. \& Zavarrone, E. (2017). Performance measurement in tourism firms: A content analytical meta-approach. Tourism Management, 59, 36-56.

Saraniemi, S. \& Kylänen, M. (2011). Problematizing the Concept of Tourism Destination: An Analysis of Different Theoretical Approaches. Journal of Travel Research, 50(2), 133-143.

SEGITTUR - Sociedad Estatal para la Gestión de la Innovación y las Tecnologías Turísticas. (2014). Destinos Turísticos Inteligentes - Informe de análisis, diagnóstico y recomendaciones de Palma de Mallorca. Disponível em: <smartoffice.palma. 
Actas del Seminario Internacional Destinos Turísticos Inteligentes:

nuevos horizontes en la investigación y gestión del turismo

Universidad de Alicante, 26 y 27 de octubre de 2017

cat/portal/PALMA/smartoffice/RecursosWeb/DOCUMENTOS/1/0_98401_1. $\mathrm{pdf}>$.

- (2015). Smart destinations report: building the future. Disponível em: <www. segittur.es/opencms/export/sites/segitur/.content/galerias/descargas/documentos/Libro-Destinos-Inteligentes-en-Ingls.pdf>.

Teixeira, E. C. (2002). O papel das políticas públicas no desenvolvimento local e na transformação da realidade. Salvador: AATR-BA.

Tu, Q. \& Liu, A. (2014). Framework of Smart Tourism Research and Related Progress in China. In: International Conference on Management and Engineering (CME 2014). DEStech Publications, 140-146.

Velasco González, M. (2010). Gobernanza del turismo: retos y estrategias de las redes de destinos turísticos. CES Felipe II. Universidad Complutense.

- (2011). La política turística: una arena de acción autónoma. Cuadernos de Turismo, 27, 953-969.

- (2013). Gestión pública del turismo. La gobernanza. In: Pulido Fernández, I. J. \& López Sánchez, Y. (Eds.). Gestión estratégica sostenible de destinos turísticos. Sevilla: Universidad Internacional de Andalucía, 469-519.

- (2014). Gobernanza turística: ¿Políticas públicas innovadoras o retórica banal? Caderno Virtual de Turismo. Edição especial: Hospitalidade e políticas públicas em turismo, 14, 9-22.

Vergara, A. \& Rivas, J. L. de las. (2004). Territorios inteligentes. Madrid: Fundación Metrópoli.

Zehrer, A.; Raich, F.; Siller, H. \& Tschiderer, F. (2014). Leadership networks in destinations. Tourism Review. 69(1), 59-73. 